E-JURNAL EKONOMI DAN BISNIS UNIVERSITAS UDAYANA
Available online at https://ojs.unud.ac.id/index.php/EEB/index
Vol. 10 No. 04, April 2021, pages: 223-230
e-ISSN: 2337-3067

\title{
KEPUTUSAN STRATEGIS PELAKU UMKM DALAM MENGHADAPI KRISIS EKONOMI
}

\author{
Luh Diah Citra Resmi Cahyadi ${ }^{1}$ Ni Luh Putu Sri Purnama Pradnyani²
}

\begin{tabular}{|c|c|}
\hline Article history: & Abstract \\
\hline $\begin{array}{l}\text { Submitted: } 21 \text { Januari } 2021 \\
\text { Revised: } 17 \text { Februari } 2021 \\
\text { Accepted: } 28 \text { Februari } 2021\end{array}$ & $\begin{array}{l}\text { This research aims to find out the strategic decision making } \\
\text { made by MSME entrepreneurs in facing the crisis caused by the Covid-19 } \\
\text { pandemic. The choice that can be taken by MSMEs is to do staretgi } \\
\text { retrenchment and turn around strategies in order to survive in times of } \\
\text { crisis. This research was conducted in Denpasar city and took } 75 \\
\text { samples of MSMEs focused on the leading creative economy subsectors, }\end{array}$ \\
\hline $\begin{array}{l}\text { Keywords: } \\
\text { Retrenchment Strategy; } \\
\text { Turn Around Strategy; } \\
\text { MSMEs; }\end{array}$ & $\begin{array}{l}\text { namely fashion, craft and culinary. The results of this study found that } \\
\text { the age indicators and educational background of MSMEs have a } \\
\text { positive and significant effect while the internal locus of control } \\
\text { indicators and the number of employees have a negative and significant } \\
\text { effect on the decision of MSMEs using retrenchment. While all indicators } \\
\text { do not have a significant effect on the decision of MSMEs using turn } \\
\text { around strategies. }\end{array}$ \\
\hline
\end{tabular}

\section{Kata Kunci:}

Strategi Retrenchment; Strategi Turn Around; UMKM;

\section{Koresponding:}

Universitas Dhyana Pura, Bali, Indonesia

Email:

diahcitraresmi@undhirabali.ac. id

\begin{tabular}{l} 
Abstrak \\
\hline \\
Penelitian ini bertujuan untuk mengetahui pengambilan keputusan \\
strategis yang dilakukan oleh pengusaha UMKM dalam menghadapi krisis \\
akibat pandemi Covid-19. Pilihan yang dapat diambil pelaku UMKM \\
adalah dengan melakukan strategi retrenchment dan strategi turn around \\
agar dapat bertahan dalam masa krisis. Penelitian ini dilakukan di Kota \\
Denpasar dan mengambil 75 sampel UMKM yang difokuskan pada \\
subsektor ekonomi kreatif unggulan yaitu fashion, kriya dan kuliner. Hasil \\
dari penelitian ini menemukan bahwa indikator umur dan latar belakang \\
pendidikan pelaku UMKM berpengaruh positif dan signifikan sedangkan \\
indikator internal locus of control dan jumlah karyawan berpengaruh \\
negatif dan signifikan terhadap keputusan pelaku UMKM menggunakan \\
strategi retrenchment. Sedangkan semua indikator tidak berpengaruh \\
signifikan terhadap keputusan pelaku UMKM menggunakan strategi turn \\
around.
\end{tabular}

Universitas Dhyana Pura, Bali, Indonesia ${ }^{2}$ 


\section{PENDAHULUAN}

Usaha Mikro Kecil dan Mengengah (UMKM) memiliki peranan yang besar dalam perekonomian Indonesia. Saat terjadi krisis ekonomi, UMKM dapat bertahan dibandingkan perusahaan besar. Beberapa faktor yang mempengaruhi ketahanan UMKM pada masa krisis adalah produk yang didominasi oleh bahan baku lokal sehingga mengurangi ketergantungan terhadap sector swasta asing dan produk yang dibuat memang sesuai dengan kebutuhan masyarakat, sehingga UMKM dapat merespon permintaan di pasar dengan lebih cepat (Asia, 2006), (Mourougane, n.d.,2012)

Kondisi berbeda di hadapi oleh UMKM pada masa pandemic Covid-19 yang sekarang ini telah mewabah hampir keseluruh negara-negara di dunia telah megancam ketahanan kesehatan global dan berdampak pada kondisi ekonomi dunia. Himbauan untuk melakukan physical distancing memaksa semua orang untuk berdiam diri di rumah selama masa pendemi. Di beberapa tempat juga menerapkan pembatasan aktivitas warga dengan skala lebih besar. Pembatasan untuk keluar rumah dan beraktivitas membawa dampak langsung terhadap perekonomian. Asian Development Bank (ADB) merilis bahwa pada tahun 2020 pertumbuhan ekonomi Indonesia hanya akan tumbuh sebesar 2,5 persen. Angka ini menunjukkan penurunan yang signifikan dibandingkan tahun 2019 sebesar 5 persen (Baldwin \& Weder, n.d., Haushofer \& Metcalf, 2020, Jandoc et al., 2020). Penurunan pertumbuhan ekonomi akibat pandemic ini juga akan mempengaruhi sector ekonomi yang menjadi andalan Indonesia yaitu usaha mikro kecil dan menengah (UMKM). UMKM terpengaruh dari dua sisi yaitu sisi permintaan dan sisi penawaran. Di sisi penawaran, perusahaan mengalami pengurangan pasokan tenaga kerja, karena pekerja tidak sehat atau perlu merawat anak-anak atau tanggungan lainnya. sementara sekolah ditutup dan pergerakan orang dibatasi. Langkah-langkah untuk mengatasi penyakit ini melalui lockdown dan karantina menyebabkan penurunan pemanfaatan kapasitas yang lebih parah. Selain itu, rantai pasokan terputus yang menyebabkan kekurangan suku cadang dan barang setengah jadi. Di sisi permintaan, hilangnya permintaan dan pendapatan yang tiba-tiba untuk UMKM sangat memengaruhi kemampuan mereka untuk berfungsi, dan menyebabkan kekurangan likuiditas yang parah. Lebih jauh, konsumen mengalami kehilangan pendapatan, ketakutan akan penularan dan ketidakpastian yang meningkat, yang pada gilirannya mengurangi pengeluaran dan konsumsi. Efek ini diperparah karena pekerja diberhentikan dan perusahaan tidak dapat membayar gaji. Beberapa sektor, seperti pariwisata dan transportasi, sangat terpengaruh, juga berkontribusi pada berkurangnya kepercayaan bisnis dan konsumen.

Secara umum, UMKM cenderung lebih rentan terhadap 'jarak sosial' daripada perusahaan lain (Mourougane, n.d.,2012, Bourletidis, 2013). Dalam kondisi yang penuh dengan ketidakpastian ini, UMKM akan terkena financial distress sehingga diperlukan mengambil langkah strategis untuk mempertahankan usahanya pada masa krisis dan melakukan recovery. Salah satu strategi yang dapat dilakukan oleh UMKM agar dapat bertahan pada masa krisis adalah strategi rentrenchment. Pada penelitian sebelumnya, strategi retrenchment yang umumnya dilakukan oleh perusahaan adalah dengan mengurangi sebagian aset perusahaan untuk penghematan biaya dan menanggulangi menurunnya keuntungan. Pada umumnya langkah konkritnya berupa pengurangan biaya (cost reduction) dan pengurangan aset (asset reduction). Pengurangan biaya antara lain: pengurangan tenaga kerja dengan pensiun dini atau pemberhentian sementara pada pegawai, tidak membeli peralatan (cukup menyewa), pemakaian peralatan selama mungkin, menurunkan volume produksi, dan mengurangi intensitas kegiatan promosi. Sedangkan pengurangan aset perusahaan, antara lain: dengan menjual aset perusahaan seperti tanah, bangunan, dan atau peralatan yang tidak penting, dan menghilangkan atau mengurangi fasilitas yang dinikmati kelompok tertentu (Schmitt \& Raisch, 2013) 
Penelitian sebelumnya menemukan, setelah melakukan strategi retrenchment, agar dapat recovery perusahaan akan melakukan strategi turn around. Startegi turnaround merupakan sebuah proses untuk membawa sebuah perusahaan dari situasi poor performance kepada situasi baru good sustained performance. Strategi turn around merupakan perbaikan atas kondisi ekonomi perusahaan menyusul adanya penurunan yang bersifat mengancam perusahaan. Pengambilan strategi ini bergantung pada karakteristik pelaku usaha dan karakteristik usaha itu sendiri. Faktor internal perusahaan yang mempengaruhi UMKM melakukan strategi turn around adalah ukuran perusahaan. Hasil penelitian sebelumnya mendapatkan hasil bahwa ukuran perusahaan berpengaruh positif terhadap pembuatan strategi perusahaan. Perusahaan yang lebih kecil akan lebih mudah untuk beradaptasi dengan perubahan lingkungan usaha yang dinamis dan pengambilan keputusan yang lebih cepat sehingga strategi turn around lebih mudah untuk dilakukan (Gregory et al., 2002, Sije et al., 2016, Meutia et al., 2018). Karakteristik pengusaha juga menjadi penentu dalam pengambilan keputusan terkait strategi yang akan digunakan kedepannya. Usia pelaku usaha menentukan keputusan yang akan dibuat. Hasil penelitian sebelumnya menemukan, usia berpengaruh positif terhadap pengambilan keputusan strategis. Pelaku usaha yang berusia muda, akan lebih berani dalam mengambil risiko sedangkan pelaku usaha yang berusia lanjut akan lebih berhati-hati dalam mengambil keputusan dikarenakan pengalamannya dimasa lalu. Latar belakang pendidikan pelaku UMKM juga mempengaruhi pengambilan keputusan strategis dalam suatu perusahaan. Penelitian sebelumnya menemukan bahwa latar belakang pendidikan berpengaruh positif terhadap pengambilan keputusan strategis. Pelaku UMKM yang memiliki latar belakang pendidikan yang tinggi akan memiliki kemampuan mengambil keputusan strategis yang lebih baik dibandingkan pelaku UMKM yang memilki pendidikan rendah (Kachalla, 2014, Herria , Arif Prima Johanb , Yulihasric , Rebi Fara Handika et al, 2018).

Penelitian sebelumnya menemukan bahwa internal locus of control berpengaruh positif terhadap pengambilan keputusan strategis yang dilakukan pelaku UMKM. Internal locus of control sendiri memiliki beberapa indikator yang dapat mempengaruhi pengambilan keputusan strategis yang meliputi: bekerja keras, memiliki inisiatif, selalu berusaha memecahkan masalah, selalu berusaha berpikir seefektif mungkin, dan memiliki persepsi bahwa usaha harus dilakukan jika ingin berhasil (Selart, 2005, Timofti et al., 2014, Fagbola, 2015).

Provinsi Bali merupakan salah satu daerah yang terkena dampak pandemi Covid-19. Kota Denpasar sebagai ibu kota merupakan kawasan yang memiliki kasus Covid-19 cukup tinggi, yang menyebabkan beberapa daerah harus mengalami isolasi sehingga mempengaruhi aktivitas ekonomi masyarakat, terutama pelaku UMKM. Data sensus ekonomi tahun 2016, menunjukkan Kota Denpasar memiliki UMKM sebanyak 97.277 unit yang aktivitasnya kemungkinan besar terdampak pandemi. Selain memiliki jumlah UMKM yang tinggi, Badan Ekonomi Kreatif (BEKRAF) telah menetapkan Kota Denpasar sebagai kawasan pengembangan UMKM kreatif, penelitian ini akan memfokuskan analisis pada variabel krakteristik pengusaha dengan indikator usia, latar belakang pendidikan, lama bekerja, pelatihan kewirausahaan; variabel karakteristik usaha dengan indicator sector usaha, ukuran usaha, dan umur usaha dengan variabel retrenchment sebagai variabel mediasi mempengaruhi peluang UMKM melakukan strategi turn around untuk recovery (Nations, n.d.,2009) (Andres, Lauren; Round, 2020). Berdasarkan latar belakang masalah diatas, maka dirumuskan pokok permasalahanya yaitu apakah karakteristik pengusaha dan karakteristik usaha mempengaruhi peluang pengusaha melakukan strategi turn around pada UMKM di Kota Denpasar? 


\section{METODE PENELITIAN}

Penelitian ini dilakukan di Kota Denpasar, pada bulan Agustus hingga November 2020 yang akan diuji dalam penelitian ini meliputi variable karakteristik pengusaha (X1), variabel karakteristik usaha (X2), variabel strategi retrenchment (Y1) dan strategi turn around (Y2).

Populasi yang digunakan adalah perusahaan industri kreatif yang bergerak dalam subsektor fashion, kriya, dan kuliner di Kota Denpasar. Pengambilan sampel menggunakan purposive sampling, yaitu pengambilan sampel tidak acak dengan berdasarkan kriteria-kriteria tertentu, sebagai berikut: Pengusaha UMKM kreatif yang bergerak pada sub sector fashion, kuliner dan kriya, usaha berlokasi di Kota Denpasar dan usaha telah berjalan selama minimal 5 tahun. Populasi dalam penelitian ini adalah sebanyak 634 UMKM bidang fashion, kuliner dan kriya sedangkan sampel yang digunakan dalam penelitian ini adalah 75 UMKM.

Pengumpulan data dalam penelitian ini dilakukan dengan tiga cara. Obeservasi dilakukan dengan cara observasi non perilaku dalam bentuk data jumlah industri kecil dan tenaga kerja Kota Denpasar. Wawancara dilakukan dengan wawancara terstruktur dengan menggunakan daftar pertanyaan dan yang terakhir adalah wawancara mendalam, yaitu metode pengumpulan informasi secara lebih terbuka.

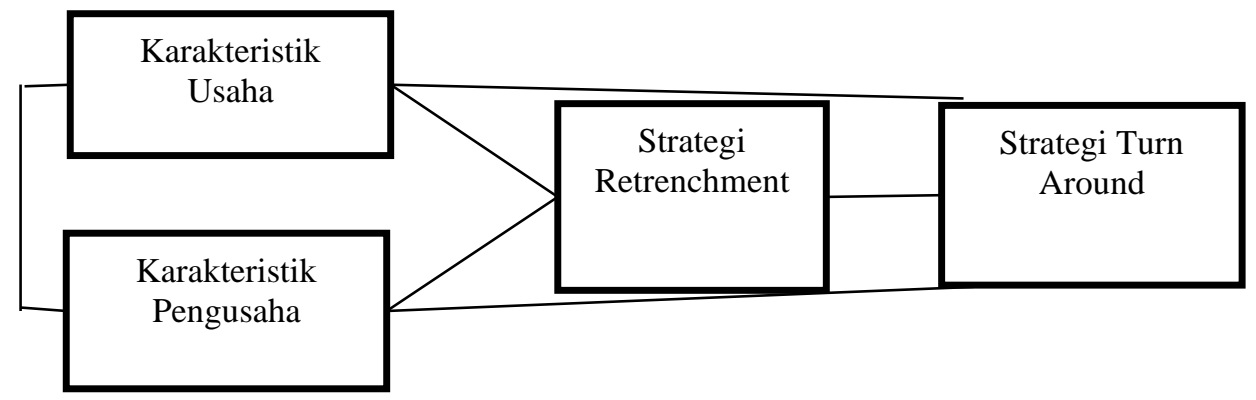

Gambar 1.

Kerangka Penelitian

Teknik analisis data yang digunakan dalam penelitian ini adalah regresi linier berganda menggunakan STATA14 dengan persamaan regresi logistik sebagai berikut:

Substruktural 1:

$$
\mathrm{Y} 1=\alpha+\beta_{1} \mathrm{X}_{1}+\beta_{2} \mathrm{X}_{2}+\beta_{3} \mathrm{X}_{3}+\beta_{4} \mathrm{X}_{4}+\mathrm{e}
$$

Substruktural 2:

$$
\mathrm{Y} 2=\alpha+\beta_{1} \mathrm{X}_{1}+\beta_{2} \mathrm{X}_{2}+\beta_{3} \mathrm{X}_{3}+\beta_{4} \mathrm{X}_{4}+\beta_{5} \mathrm{Y}_{1}+\mathrm{e}
$$

Keterangan:

$\mathrm{X} 1=$ Umur

$\mathrm{X} 2$ = Latar Belakang Pendidikan

$\mathrm{X} 3=$ Internal Locus of Control

$\mathrm{X} 4 \quad=$ Jumlah Tenaga Kerja

$\mathrm{Y} 1=$ Strategi Retrenchment

Y2 = Strategi Turn Around 


\section{HASIL DAN PEMBAHASAN}

Hasil regresi ordinal pada Tabel 1 substruktural pertama mendapatkan hasil sebagai bahwa variabel karakteristik usaha dengan indikator umur pelaku UMKM berpengaruh positif terhadap peluang pengusaha melakukan strategi retrenchment saat krisis ekonomi terjadi. Hasil ini mendukung hasil penelitian sebelumnya yang menyatakan bahwa hasil ini mendukung hasil penelitian sebelumnya, yaitu pengusaha yang berusia muda akan lebih berani dalam pengambilan keputusan yang memiliki risiko tinggi sedangkan pengusaha yang sudah berusia lanjut akan lebih mempertimbangkan banyak aspek dalam perusahaan sebelum melakukan pengambilan keputusan terutama keputusan yang memiliki risiko tinggi.

Tabel 1.

Hasil Regresi Ordinal Substruktural 1

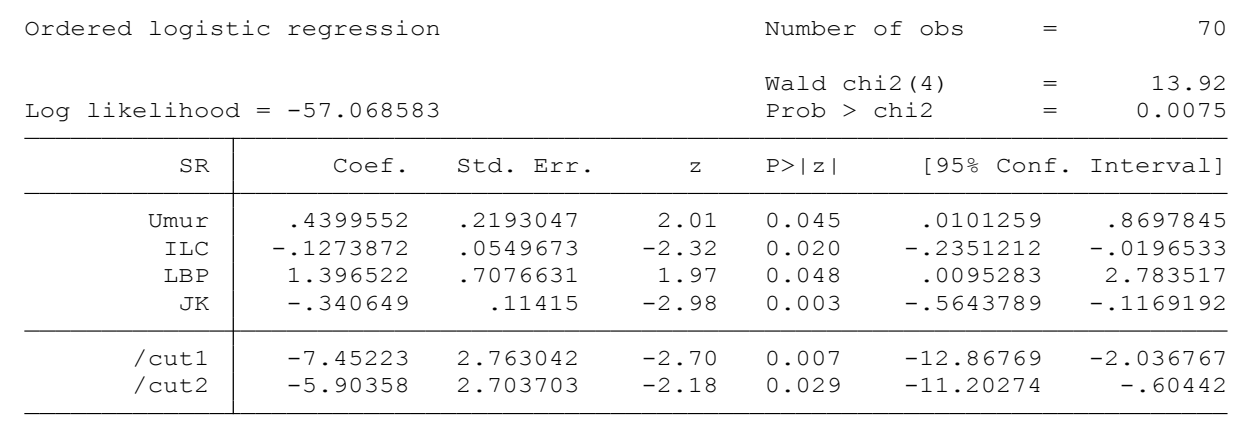

Sumber: Hasil Penelitian (2020)

Indikator latar belakang pendidikan berpengaruh positif terhadap keputusan pelaku UMKM untuk melakukan retrenchment saat perekonomian mengalami krisis. Hasil ini mendukung hasil penelitian sebelumnya dimana latar belakang pendidikan pengusaha juga menjadi factor yang dapat mempengaruhi pengambilan keputusan strategis dalam perusahaan. Pelaku UMKM yang memiliki pendidikan tinggi akan mengambil keputusan strategis yang lebih baik dibandingkan yang berpendidikan rendah.

Sedangkan internal locus of control berpengaruh negatif dan signifikan terhadap keputusan pengusaha menggunakan strategi retrenchment dalam menghadapi krisis ekonomi. Hasil ini berlawanan dengan hasil penelitian sebelumnya, dimana hasil penelitian sebelumnya menemukan bahwa internal locus of control berpengaruh positif terhadap keputusan pengusaha menggunakan strategi retrenchment dalam menghadapi krisis ekonomi. Locus of control terkait dengan tingkat kepercayaan seseorang tentang peristiwa, nasib, keberuntungan dan takdir yang terjadi pada dirinya. Individu yang percaya bahwa peristiwa, kejadian, dan takdir disebabkan karena kendali dirinya sendiri disebut dengan internal locus of control. Dalam penelitian ini, pelaku usaha tidak yakin bahwa pengurangan karyawan dapat membantu mempertahankan usaha mereka dimasa depan. Hal ini dikarenakan pelaku UMKM menganggap karyawan merupakan aset penting perusahaan dan adanya harapan yang besar akan perbaikan kondisi ekonomi dimasa yang akan datang. Strategi lain yang diambil pelaku usaha untuk mengatasi masalah ini adalah dengan menggunakan sistem half day work, membatasi hari kerja karyawannya, atau mengurangi gaji yang diberikan.

Variabel karakteristik perusahaan yang dilihat dari jumlah karyawan menunjukkan hasil yang negatif dan signifikan terhadap keputusan pengusaha menggunakan strategi retrenchment dalam 
menghadapi krisis ekonomi. Hasil ini berlawanan dengan hasil penelitian sebelumnya yang menyatakan bahwa jumlah karyawan berpengaruh positif terhadap keputusan pengusaha melakukan strategi retrenchment dalam menghadapi krisis ekonomi. Mengikuti indikator internal locus of control, dalam penelitian ini pelaku UMKM tidak melakukan pengurangan karyawan untuk bertahan dalam menghadapi krisis tetapi dengan pengaturan sistem kerja dan pengurangan gaji.

Tabel 2.

Regresi Ordinal Substruktural 2

\begin{tabular}{|c|c|c|c|c|c|c|c|}
\hline \multicolumn{4}{|c|}{ Ordered logistic regression } & \multicolumn{2}{|c|}{ Number of obs } & $=$ & 70 \\
\hline Log likelihoo & $=-40.2309$ & & & Wald & $2(5)$ & $\begin{array}{l}= \\
=\end{array}$ & $\begin{array}{r}4.44 \\
0.4880\end{array}$ \\
\hline STA & Coef. & Std. Err. & $\mathrm{z}$ & $P>|z|$ & {$[95 \%$} & Conf. & Interval] \\
\hline SR & -.1802254 & .4014712 & -0.45 & 0.653 & -.967 & 0944 & .6066436 \\
\hline Umur & -.1349717 & .2073224 & -0.65 & 0.515 & -.541 & 3161 & .2713726 \\
\hline ILC & .0066108 & .0558244 & 0.12 & 0.906 & -.102 & 8031 & .1160246 \\
\hline LBP & -.7397371 & .7876593 & -0.94 & 0.348 & -2.28 & 3521 & .8040468 \\
\hline JK & .0796248 & .1352239 & 0.59 & 0.556 & -.185 & 4092 & .3446587 \\
\hline /cut 1 & -2.635004 & 2.920704 & -0.90 & 0.367 & -8.35 & 9479 & 3.089471 \\
\hline
\end{tabular}

Sumber: Hasil Penelitian (2020)

Berdasarkan hasil regresi ordinal pada tabel 2 diperoleh hasil variabel karakteristik pengusaha yang meliputi umur, internal locus of control, dan latar belakang pendidikan tidak berpengaruh signifikan terhadap keputusan pengusaha melakukan strategi turn around dalam menghadapi krisis ekonomi. Variabel karakteristik perusahaan yang menggunakan indikator jumlah karyawan tidak berpengaruh signifikan terhadap keputusan pengusaha melakukan strategi turn around dalam menghadapi krisis ekonomi. Strategi retrenchment sebagai pemoderasi tidak signifikan dalam memperkuat atau memperlemah keputusan pengusaha dalam mengambil keputusan melakukan strategi turn around saat mengalami krisis ekonomi.

Proses turn around terdiri dari 2 bagian, yaitu: menahan penurunan (decline stemming strategy) dan strategi pemulihan (recovery strategy). Decline stemming strategy bertujuan untuk menstabilisasi kondisi keuangan perusahaan, menghilangkan ketidak efisienan dan menstabilkan suasana internal perusahaan. Ketika kondisi keuangan perusahaan stabil, maka dapat dilakukan strategi pemulihan (Liou \& Smith, 2011).

Dalam penelitian ini, karakteristik perusahaan dan karakteristik pengusaha tidak berpengaruh signifikan terhadap keputusan pengusaha menggunakan strategi turn around dalam memutar arah usahanya agar dapat bangkit setelah menghadapi krisis ekonomi. Pelaku UMKM belum memikirkan pilihan menggunakan strategi putar arah dikarenakan masih fokus mempertahankan perusahaan dengan strategi retrenchment dan akan memikirkan strategi pemulihan setelah mendapat kepastian dari pemerintah mengenai perkembangan perekonomian kedepannya.

\section{SIMPULAN DAN SARAN}

Umur dan latar belakang pendidikan berpengaruh positif dan signifikan terhadap keputusan pelaku UMKM melakukan strategi retrenchment. Internal locus of control dan jumlah karyawan pengaruh negatif dan signifikan terhadap keputusan pelaku UMKM melakukan strategi retrenchment saat menghadapi krisis ekonomi. Implikasi dari hasil penelitian ini menunjukkan bahwa semakin 
dewasa usia pelaku usaha dan semakin tinggi tingkat pendidikan pelaku usaha tersebut, maka pelaku usaha akan segera melakukan tindakan strategis saat perekonomian mengalami krisis ekonomi, akan tetapi dalam masa pandemi Covid-19 strategi retrenchment yang dilakukan tidak secara langsung melakukan pengurangan biaya melalui pemutusan hubungan kerja kepada karyawan. Pelaku UMKM mempertimbangkan beberapa pilihan pengurangan biaya dengan merumahkan karyawan, bekerja dengan sistem shift dan menjual beberapa barang modal yang dianggap kurang produktif hal ini dilakukan karena pengusaha masih memiliki harapan bahwa kondisi perekonomian akan segera membaik.

Umur, latar belakang pendidikan, internal locus of control, dan jumlah karyawan tidak berpengaruh terhadap keputusan pelaku UMKM dalam melakukan strategi turn around. Strategi retrenchment sebagai moderasi tidak memperkuat atau memperlemah keputusan pelaku UMKM untuk melakukan strategi turn aroud saat perekonomian mengalami krisis ekonomi. Implikasi dari hasil penelitian ini pelaku UMKM masih belum mempertimbangkan strategi turn around sebagai rencana strategis yang akan dilakukan saat perekonomian mengalami recovery. Beberapa alasan pelaku UMKM meliputi belum memikirkan rencana kedepan mengingat usahanya masih dalam masa bertahan agar dapat melalui pandemi Covid 19 dan masih ragu dengan perkembangan ekonomi kedepan. Batasan dari penelitian ini, jumlah variabel yang diambil masih terbatas pada strategi retrenchment dan strategi turn around, sedangkan pelaku UMKM bisa saja mengambil strategi lain dalam menjalankan usahanya pada masa pandemi Covid-19. Selain variabel karakteristik usaha dan karakteristik pengusaha, masih banyak lagi faktor internal dan eksternal yang juga mempengaruhi keputusan pelaku usaha dalam mengambil keputusan strategis.

\section{REFERENSI}

Andres, Lauren; Round, J. (2020). The creative economy in a context of transition: A review of the mechanisms of micro-resilience. https://doi.org/10.1016/j.cities.2015.02.003

Asia, S. (2006). CHAPTER III DEVELOPMENT OF SMEs IN INDONESIA OF SSIs IN INDONESIA. May, 1(2) $1-13$.

Baldwin, R., \& Weder, B. (n.d.). Economics in the Time of COVID-19.

Bourletidis, K. (2013). The strategic management of market information to SMEs during economic crisis . Procedia - Social and Behavioral Sciences, 73(5), 598-606. https://doi.org/10.1016/j.sbspro.2013.02.096

Fagbola, O. O. (2015). Influence of Locus of Control, Work Motivation and Information Use on Decisionmaking of Managers in the Aviation Industry in Nigeria .

Gregory, G., Harvie, C., Lee, H., \& Harvie, C. (2002). University of Wollongong Department of Economics Working Paper Series 2002 Korean SMEs in the Wake of the Financial Crisis : Strategies, Constraints , and Performance in a Global Economy.

Haushofer, J., \& Metcalf, C. J. E. (2020). Combining behavioral economics and infectious disease epidemiology to mitigate the COVID-19 outbreak *.

Herria , Arif Prima Johanb , Yulihasric , Rebi Fara Handika d, M. A. (2018). Turnaround strategy from the perspective of strategic leadership: conceptual review. July 2016.

Jandoc, K., Mendoza, A., \& Quimbo, S. L. (2020). UP School of Economics Discussion Papers.

Kachalla, B. (2014). Entrepreneurial Characteristics of Strategic Decision-Making and the Difference from Managers. 4(5), 87-98. https://doi.org/10.5901/jesr.2014.v4n5p87

Liou, D.-K., \& Smith, M. (2011). Financial Distress and Corporate Turnaround: A Review of the Literature and Agenda for Research. SSRN Electronic Journal, 8(1), 1-32. https://doi.org/10.2139/ssrn.925596

Meutia, M., Ismail, T., \& Ummi, N. (2018). LEADERSHIP ISSUE AND SME PERFORMANCE. 9(4), 424-435.

Mourougane, A. (n.d.). Promoting SME development in Indonesia. 995.

Nations, U. (n.d.). and Micro \& Small Scale Enterprise Development A Contribution to Poverty Alleviation Creative Industries and Micro \& Small Scale Enterprise Development A Contribution to Poverty Alleviation.

Schmitt, A., \& Raisch, S. (2013). Corporate Turnarounds : The Duality of Retrenchment and Recovery Achim 
Schmitt and Sebastian Raisch. November. https://doi.org/10.1111/joms.12045

Selart, M. (2005). Understanding the role of locus of control in consultative decision-making: a case study. 43(3), 397-412. https://doi.org/10.1108/00251740510589779

Sije, A., Omwenga, J., \& Iravo, M. (2016). Relationship Between Reorganization Turnaround Strategy And Performance Of Small And Medium Enterprises In Kenya. 18(9), 134-138. https://doi.org/10.9790/487X180903134138

Timofti, I. C., Nechita, E., \& Dumitriu, G. (2014). The Influence of the Locus of Control and Decision-making Capacity upon the ScienceDirect The Influence of the Locus of Control and Decision-making Capacity upon the Leadership Style. August. https://doi.org/10.1016/j.sbspro.2014.05.086 